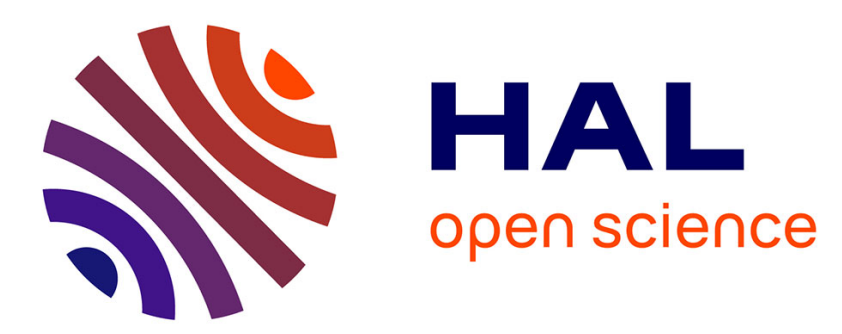

\title{
A comparison of models for predicting the true hardness of thin films
}

\author{
Alain Iost, Gildas Guillemot, Yann Rudermann, Maxence Bigerelle
}

\section{To cite this version:}

Alain Iost, Gildas Guillemot, Yann Rudermann, Maxence Bigerelle. A comparison of models for predicting the true hardness of thin films. Thin Solid Films, 2012, 524, pp.229-237. 10.1016/j.tsf.2012.10.017 . hal-01174511

\section{HAL Id: hal-01174511 \\ https://hal.science/hal-01174511}

Submitted on 23 Nov 2017

HAL is a multi-disciplinary open access archive for the deposit and dissemination of scientific research documents, whether they are published or not. The documents may come from teaching and research institutions in France or abroad, or from public or private research centers.
L'archive ouverte pluridisciplinaire HAL, est destinée au dépôt et à la diffusion de documents scientifiques de niveau recherche, publiés ou non, émanant des établissements d'enseignement et de recherche français ou étrangers, des laboratoires publics ou privés. 


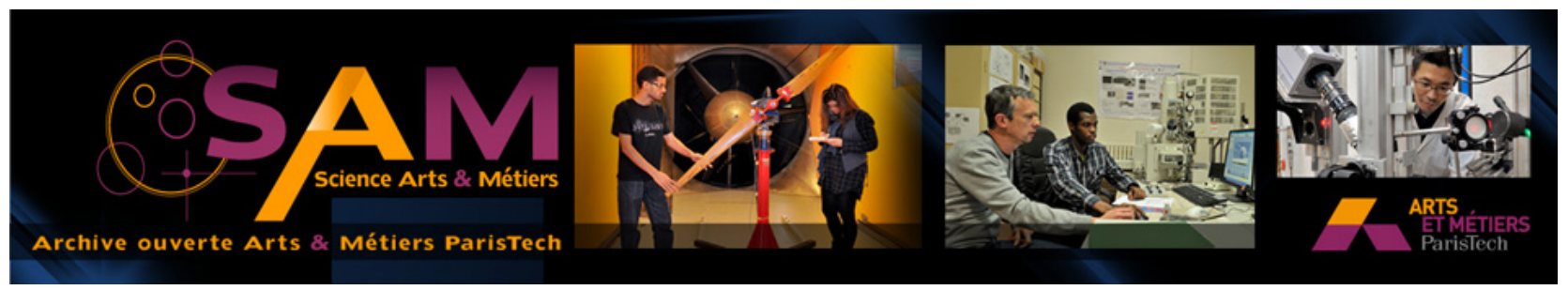

Science Arts \& Métiers (SAM)

is an open access repository that collects the work of Arts et Métiers ParisTech researchers and makes it freely available over the web where possible.

This is an author-deposited version published in: http://sam.ensam.eu

Handle ID: .http://hdl.handle.net/10985/9742

\section{To cite this version :}

Alain IOST, Gildas GUILLEMOT, Yann RUDERMANN, Maxence BIGERELLE - A comparison of models for predicting the true hardness of thin films - Thin Solid Films - Vol. 524, p.229-237 2012 


\title{
A comparison of models for predicting the true hardness of thin films
}

\author{
Alain Iost ${ }^{\mathrm{a}, \mathrm{b}, *}$, Gildas Guillemot ${ }^{\mathrm{a}, \mathrm{b}}$, Yann Rudermann ${ }^{\mathrm{a}}$, Maxence Bigerelle ${ }^{\mathrm{c}, \mathrm{d}}$ \\ a Arts et Metiers ParisTech, 8 Boulevard Louis XIV, F-59000 Lille, France \\ b LML, CNRS UMR 8107, F-59000 Lille, France \\ c Laboratoire Roberval, CNRS FRE 2833, UTC Centre de Recherches de Royallieu, BP 20529 Compiègne, France \\ d UVHC, TEMPO EA 4542, LAMIH UMR 8530, F-59313 Valenciennes, France
}

Keywords:

Hardness testing

Composite hardness

Instrumented indentation

Coatings

Thin films

\begin{abstract}
A B S T R A C T
Instrumented indentation is widely used to characterize and compare the mechanical properties of coatings. However, the interpretation of such measurements is not trivial for very thin films because the hardness value recorded is influenced by both the deformation of the film and that of the substrate. An approach to extract the mechanical properties of films or coatings as an alternative to the experimental hardness measurement versus the indentation depth involves the use of composite hardness models. However, there are always uncertainties and difficulties in correctly deconvoluting the film hardness in experiments on composite materials. To justify their approach, some authors argue that their model is correct if the predicted hardness obtained for the coating provides a good fit to the experimental data. This condition is, of course, necessary, but it is not sufficient. A good fit to the experimental curve does not guarantee that a realistic value of the film hardness is deduced from the model. In this paper, different models to describe the composite hardness were tested by indenting a Ni-P coating. Its thickness was chosen to be sufficiently large such that its mechanical properties were perfectly known. We show that some models extensively used in the literature are inadequate to extract the film-only hardness without the effects of the substrate when the indentation range is too limited, although they predict the composite hardness very well.
\end{abstract}

\section{Introduction}

The characterization of the mechanical properties and, more precisely, the hardness of coatings is of paramount importance in industry because of multi-material development and the related economic stakes [1]. Coating thickness can vary significantly from approximately $10 \mathrm{~nm}$ to millimeters according to the practical application, such as microelectromechanical systems, electronics, optics, cutting tools, and protection against mechanical damage (wear, contact pressure ...) or corrosion. The instruments for measuring the hardness of coatings have various applied load $(F)$ and indenter penetration depth $(h)$ ranges, including the nano range $(h<200 \mathrm{~nm})$, micro range $(F<2 \mathrm{~N}$ and $h>200 \mathrm{~nm})$ and macro range $(2 \mathrm{~N}<\mathrm{F}<30 \mathrm{kN})$. In the same way, the units used may vary according to the tests and the types of users. It is common in the industrial environment to measure the coating hardness with a predefined load: 100 gf is the most commonly used load in mechanical construction, particularly for nickel coatings. However, this evaluation can be very different from the real value if the relative indentation depth (RID), $h / t$, where $t$ is the coating thickness, is above a critical value. When the coating hardness is twice the substrate hardness, Bückle [2] suggests that it is not possible to measure only the coating hardness if the penetration

\footnotetext{
* Corresponding author at: Arts et Metiers ParisTech, 8 Boulevard Louis XIV, F-59000 Lille, France.

E-mail address: alain.iost@ille.ensam.fr (A. Iost).
}

depth is greater than a tenth of the thickness. According to Jönsson and Hogmark [3], quoting [4], the substrate begins to contribute to the measured hardness for indentation depths of approximately 0.07-0.2 times the coating thickness; a hard coating on a softer substrate is the most unfavorable case. However, it is necessary to avoid generalizing too quickly because some models or simulations give different results. Tuck et al. [5] report that, for a couple of $3.75 \mu \mathrm{m}$ thick $\mathrm{ZrN} /$ steel sheets with an RID equal to 0.1 , the measured hardness was only $88 \%$ of the coating hardness. In the case where the ratios between the yield strength and the Young's modulus of the coating and the substrate are greater to 10 and 0.1 , respectively, the numerical simulations by Gamonpilas and Busso [6] show that the substrate begins to influence the hardness as soon as the penetration depth is equal to $5 \%$ of the coating thickness. The greater the differences in hardness and modulus between the hard coating and the soft substrate, the sooner the substrate begins to influence the measured hardness for small indentation depths. Nanoindentation can solve the problem in most cases when using very low loads, but other perturbing factors have to be considered, such as the passivation layer, oxide formation, the roughness, micro-structural heterogeneity, crystallographic grain orientation, indenter bluntness and indentation size effect.

It is therefore necessary to create a model for the coupled substratecoating behavior under indentation, where the substrate influences the coating hardness measured and the coating influences that of the substrate. One of the first models developed by Bückle $[2,7]$ to predict the 
hardness of the coating alone defines twelve $i$-indexed areas of influence of equal thickness. The individual contributions of the sublayers are expressed by the product $H_{i} P_{i}$ where $H_{i}$ is the intrinsic hardness of the layer $i$, and $P_{i}$ is a weight factor taking into account its distance from the surface. Thus, for a layer with a uniform hardness $H_{f}$ on a substrate with a hardness $H_{s}$, the measured hardness $H_{k}$ for a penetration depth $k$ is:

$H_{k}=\frac{\sum_{i=1}^{12} H_{i} P_{i}}{\sum_{i=1}^{12} P_{i}}=\frac{H_{f} \sum_{i=1}^{k} P_{i}+H_{s} \sum_{i=k+1}^{12} P_{i}}{\sum_{i=1}^{12} P_{i}}$.

The measured hardness, $H_{k}$, that we shall call "composite hardness" $H_{c}$, includes the coating hardness $H_{f}$, and the substrate's one $H_{s}$ according to the formula:

$\frac{H_{c}-H_{s}}{H_{f}-H_{s}}=\frac{\sum_{i=1}^{k} P_{i}}{\sum_{i=1}^{12} P_{i}}=a$

where the coefficient $a$ varies between $0\left(H_{c}=H_{s}\right)$ and $1\left(H_{c}=H_{f}\right)$.

Nearly all models designed to determine the coating hardness are expressed according to this formula. The a-coefficient of the model depends on the coating thickness, the penetration depth (for a perfect Vickers diamond, $h$ is equal to a seventh of the print diagonal $d$ ) and various adjustable parameters determined empirically or based on physical considerations. We also considered the so-called indentation size effect (ISE), i.e., the apparent hardness increases with decreasing load for a massive material according to the relation:

$H_{f}=H_{0 f}+\frac{B_{f}}{h}=H_{0 f}\left(1+\alpha_{f} \frac{t}{h}\right)$ and $H_{s}=H_{0 s}+\frac{B_{s}}{h}=H_{0 s}\left(1+\alpha_{s} \frac{t}{h}\right)$

in which the subscripts $f$ and $s$ are related to the film and the substrate, respectively; $B$ and $\alpha$ are constants; $H_{0}$ is the so-called absolute hardness i.e. the macrohardness independent of the applied load; the slope $B$ is related to the ISE, and $t$ is an arbitrary value taken in this work to be the coating thickness. The right-hand side of these equalities was chosen because $\alpha$ is dimensionless. This variation has been validated by Farges and Degout [8], who considered the pile-up formation around the prints. This piling supports the load [9], which we verified by calculating the real indenter/specimen contact surfaces for aluminum, titanium alloys and steels [10].

Authors who propose a new model generally justify its reliability by showing that the knowledge of $H_{s}$ and the results assumed for $H_{f}$ determine $H_{c}$ with a good approximation. This validation is not relevant because the unknown value is not the "composite" hardness, which is experimentally measured, but the hardness of the coating. To avoid this error, our study of the robustness of various models is based on a material with a coating of sufficient thickness so that its hardness can be measured independently. We propose a methodology to estimate the robustness of various models to predict the 'true' hardness of a coating. Hardness measurements are thus developed for a composite material corresponding to this coating deposited on a metallic substrate. A robust model is not necessarily valid, but a model that is not robust can lead to an erroneous evaluation of the coating hardness if the experiments entail uncertainties.
The paper is organized as follows. In the next section, we briefly introduce three well-known models, called Jönsson and Hogmark (JH), Korsunsky (K) and Puchi-Cabrera (PC), which are used to deduce the coating hardness from experimental data. We then provide the experimental conditions (tested specimen and load-indentation depth measurements) in Section 3. Section 4 is devoted to the precise description of the methodology used to study the robustness of the three models, analyze the results and compare the predictions for the film hardness obtained by the various models when the experimental data are noisy (corresponding to measurement errors) or truncated (corresponding to the limits of the experimental device). The paper ends with some conclusions in Section 5 on the robustness of the models.

\section{The three models under study}

Since the pioneering work of Bückle, several models to express the composite hardness as a function of the film and substrate hardnesses have been proposed in the literature. We shall limit our work to the most often cited models that do not include the Young's modulus of the coating, which can differ noticeably from that of the bulk material because of the microstructure (e.g., columnar microstructure or crystallographic texture), the gradient of the chemical composition or the residual stresses. The nanohardness measurement is often possible but difficult when the coating is very thin because it is influenced by the substrate. The nanohardness is generally higher than the micro or macrohardnesses because of the indentation size effect (ISE) [10]. The three models critically examined have been widely applied due to their simplicity and are cited by more than 1000 papers in Scopus. They are described very briefly, and the reader will be able to find further information in the references provided below.

\subsection{The Jönsson and Hogmark model [3] (JH)}

This model, which is among the oldest, assumes that the composite hardness can be expressed using an area law of mixture of the indented surfaces in the film and the substrate:

$H_{c}=\frac{A_{f}}{A} H_{f}+\frac{A_{s}}{A} H_{s}$

where $A_{f}$ and $A_{s}$ are the load supporting area of the film and the substrate, respectively, and $A=A_{f}+A_{s}$ the total area on which the mean pressure acts.

From simple geometric considerations, the $a$-coefficient was found to be:

$a=\frac{2 C t}{h}-\frac{C^{2} t^{2}}{h^{2}}=\frac{A_{f}}{A}=1-\frac{A_{s}}{A}$

where $C$ is a constant that depends on the geometry of the indenter and on the film deformation during indentation. For a Vickers indenter, $C$ takes the value of 0.140 if the coating is plastically deformed during the indentation to accommodate the shape of the indenter or 0.0727 if crack formation occurs in the coating. We must emphasize that the $a$-coefficient should be between 0 and 1. Consequently, if $h$ is lower than $C t$ (i.e., $C t / h>1$ ), the substrate does not influence the composite hardness, and $a$ is equal to 1 . Vingsbo et al. [11] provided an improvement to the first model by introducing the hardness variation with the applied load (Eq. (3)) for the coating and the substrate in the composite hardness calculation. We proposed a second improvement [12] by taking into consideration all terms in Eq. (2) (producing Eq. (6)) instead of the simplification recommended by [3,11], which consists of neglecting the $1 / h^{2}$ and $1 / h^{3}$ terms in comparison with the $1 / h$ terms in Eqs. (3)-(5). This simplification implies that the composite 
hardness is a linear function of the inverse diagonal depth, as in Eq. (3) [13], but it is without physical meaning and has only been verified in some experimental conditions [12].

$$
\begin{aligned}
H_{c}= & H_{0 s}+\frac{B_{s}+2 C t\left(H_{0 f}-H_{0 s}\right)}{h} \\
& +\frac{2 C t\left(B_{f}-B_{s}\right)-C^{2} t^{2}\left(H_{0 f}-H_{0 s}\right)}{h^{2}}-\frac{C^{2} t^{2}\left(B_{f}-B_{s}\right)}{h^{3}}
\end{aligned}
$$

Some authors added a degree of freedom to Eq. (5) by assuming that $C$ is not constant but variable $[14,15]$ or that $C$ is a function of the indentation depth in the form $C_{v} \sim(t / h)^{n}$ [16]. Both of these approaches introduce a fitting parameter and thus decrease the robustness of the model.

\subsection{The modified model of Korsunsky et al. (K) [17,18]}

Korsunsky and co-workers based their analysis on the work-ofindentation and the way the energy was expended during indentation. While searching for solutions that can determine the coating and substrate hardnesses by extrapolating to the limits, $H_{c}$, according to this model, is given by:

$H_{c}=H_{s}+\frac{\left(H_{f}-H_{s}\right)}{1+k_{k}\left(\frac{h}{t}\right)^{2}} ; k_{k}>0$.

Thus, the $a$-coefficient is defined as:

$a=\frac{1}{1+k_{k}\left(\frac{h}{t}\right)^{2}}$

where $h / t$ is the relative indentation depth and $k_{k}$ is a fitting parameter related to the film thickness. In this model, both the film and the substrate hardness are independent of the applied load because $H_{c}$ is assumed to approach the coating hardness asymptotically for an infinitely low indentation depth. Korsunsky et al. are nevertheless conscious of the limits of this hypothesis in the microhardness or macrohardness domains and propose to introduce the hardness variation with the load in another paper to be published.

In this work, we consider Eq. (7) with the ISE, as given by Eq. (3), because it is obvious from our results that the coating hardness varied with the applied load.

To improve the previous model, Korsunsky et al. introduced a complementary variable $X$ instead of the exponent " 2 " assigned to the relative indentation depth and obtained:

$a=\frac{1}{1+k_{2}\left(\frac{h}{t}\right)^{X}} ; k_{2}>0 ; X \in\{1, \ldots, 10\}$.

This model has one more constant (one degree of freedom) than Eq. (8). Therefore, as explained in Section 4, the model is less robust, which is the reason we do not present the results related to Eq. (9) below.

\subsection{The modified Puchi-Cabrera model (PC) [19]}

Puchi-Cabrera suggested a volume law of mixture (composite hardness as a function of the indented volumes in the coating and the substrate) based on a simple geometric diagram of the indented areas, which is different than the model of Jönsson and Hogmark
[3]. Two fitting parameters $k_{p}$ and $n_{p}$ are introduced in the model to improve its efficiency so that coefficient $a$ becomes:

$a=\exp \left[-k_{P}\left(\frac{h}{t}\right)^{n_{P}}\right] ; k_{p} \geq 0 ; n_{p} \geq 0$.

This equation is merely that of Bhattacharya and Nix [20] established by a finite element simulation in which $n_{p}$ is a constant equal to 1 in the case hard/soft or 2 in the case soft/hard. In fact, $n_{p}$ is often used as a variable with a value between 0.5 and 2 [21] in the model from [20]. In this last model, $k_{p}$ can be expressed according to the Young's modulus and the yield stress, but it is more often used as a wedging coefficient [22]. We assume that the coating and the substrate hardness are a function of the applied load, as in Eq. (3).

\section{Materials and experimental methods}

The material under study was a 55- $\mu$ m-thick electroless nickelphosphorus coating deposited on a stainless steel (Z12C13) shovel floodgate obturator ( $300 \mathrm{~mm}$ thick) intended for the oil industry. The $H$ properties were obtained by force controlled depth-sensing indentation measurements with a Zwick macrohardness device ZHU2.5 and a Vickers pyramidal indenter (with a square base and a $136^{\circ}$ angle between the opposing faces of the pyramid). During the instrumented indentation test, the applied load and the resulting depth of penetration of the indenter were continuously recorded, and a full set of data, including load, depth and time, were recorded. According to the manufacturer, this device can apply variable loads between 5 and $2500 \mathrm{~N}$ with an error lower than $1 \%$ and record a displacement up to $4 \mathrm{~mm}$ with a $0.04 \mu \mathrm{m}$ resolution. Because the displacement was measured directly between the surface of the indenter and the indenter tip through a glass scale, the indentation depth was deduced from the displacement after compliance correction. The load-indentation depth curve was used to determine the hardness under load [23]. The Martens hardness value $H M$ was calculated from the applied load-indentation depth curve while increasing the test load and is defined as the applied load divided by the surface area of the indenter imprints beneath the original surface, considering both the plastic and elastic response of the material tested [24]:

$H M=\frac{F}{26.43 h^{2}}$.

The hardness under the test force was called the "Martens hardness" [25] in memory of Adolf Martens, who first presented a device at the end of nineteenth century that can record the test force and indentation depth [26]. The main goal of the instrumented test is to quickly obtain a curve with one thousand load-displacement data points, which would be a huge experimental work for a classical hardness test. Fig. 1 shows the load-displacement plot recorded on the nickel/steel specimen used to study the robustness of the three models.

$H M$ corresponds exactly to the Vickers hardness, $H V$, assuming that the elastic recovery does not affect the measure of the indentation residual diagonal length. We verified both the repeatability and this assumption for the material in consideration by plotting a series of successive data at increasing peak-loads at the same location (Fig. 2) and comparing the remaining print diagonals measured after unloading by optical microscopy with the maximal penetration depth under load (Fig. 3) for measurements performed at different locations. The Vickers diagonal length measured by optical microscopy was seven times the indentation depth recorded by the testing machine, and thus every hardness value recorded in the instrumented indentation test can be transformed in Vickers hardness. The indentation depth was greater than $5.5 \mu \mathrm{m}$, and thus the surface area could be assumed to be that of an ideally shaped Vickers indenter without considering the rounding at the tip. Consequently, the results are presented as the Vickers hardness number 


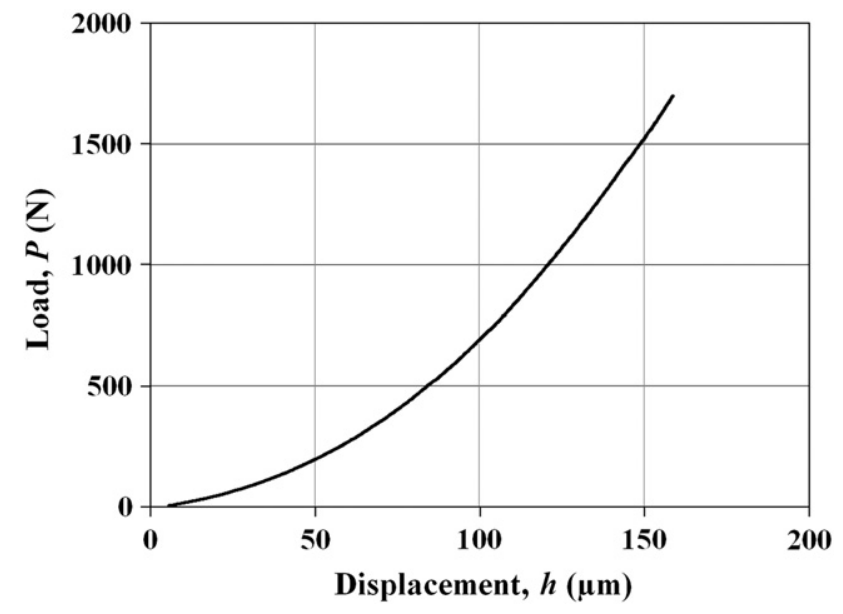

Fig. 1. The recorded indentation curve, load $F$ versus the indentation depth $h$. The first set of data ( $h$ less than approximately $8 \mu \mathrm{m}$ ) corresponds to the Ni-P coating alone, without interaction with the substrate. More than one thousand data points were recorded.

(VHN), and the units $\left(\mathrm{kgf} / \mathrm{mm}^{2}\right)$ are omitted following convention (100 $\mathrm{VHN}=0.9807 \mathrm{GPa}$ ).

The Vickers hardness is shown in Fig. 4 versus $h / t$ (RID) as commonly reported for the K and PC models and in Fig. 5 versus $t / h$ for the JH model. For the lower loads (lower indentation depths), the composite hardness varies linearly with $1 / h$ as expected for the film hardness:

$H_{f}=530+\frac{1781}{h}=530\left(1+0.06112 \frac{t}{h}\right)$

The variation of the film hardness with the load applied was verified by conventional microhardness tests performed with a Leitz "Miniload" hardness tester in the load range of $0.1-5 \mathrm{~N}$. For the maximum load, the indentation diagonal, $d$, is $33.6 \mu \mathrm{m}$ and consequently the indentation depth $(h=d / 7)$ is lower than the tenth of the coating thickness. As a result, the variation of hardness versus the reciprocal indentation depth verifies Eq. (12) that represents the film hardness. The absolute hardness $\left(H_{0 f}=530\right)$ is obtained by extrapolation to an infinite penetration depth of the experimental data lower than the 1/10th of the coating thickness.

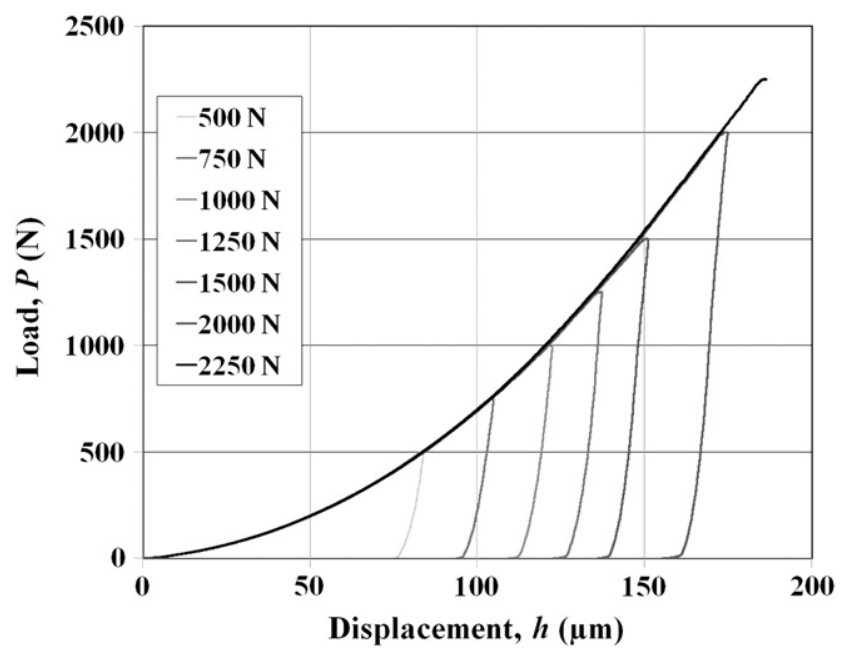

Fig. 2. Repeated force displacement curves at the same location with increasing maximum loads.
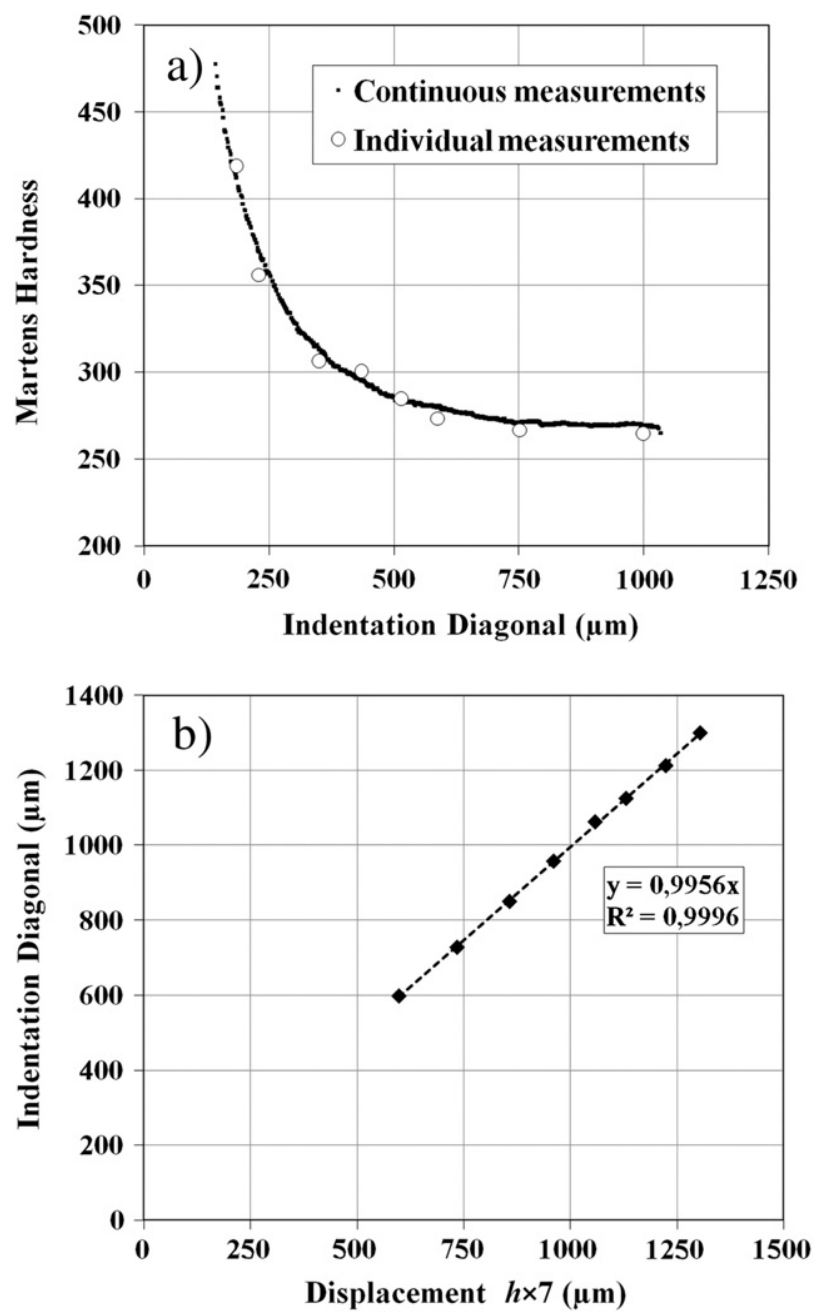

Fig. 3. a) Comparison between the Martens hardness computed from one loading curve and the Vickers hardness computed from the diagonal indentation measurement for a separate test. b) Comparison between individual optical measurements of the indentation diagonal after unloading and the indentation diagonal under load (i.e., $7 \times$ indentation depth under load).

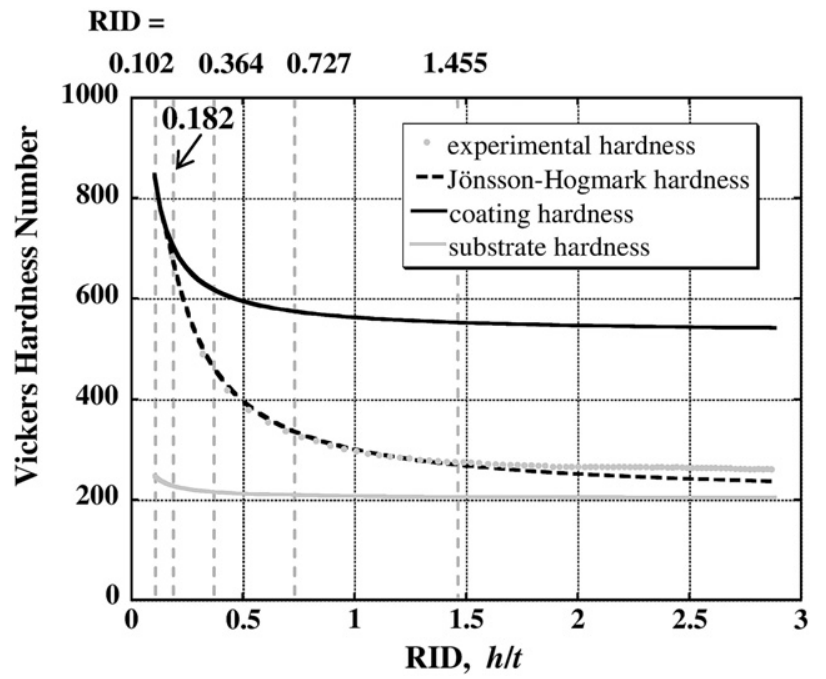

Fig. 4. Interpretation of the recorded data in Fig. 1 by plotting the Vickers hardness number versus the relative indentation depth $(\mathrm{RID}=h / t)$ and the data range used for testing the robustness of the models (RID $\geq 0.102$ to $R I D \geq 1.455$ ). The coating and substrate hardness plots correspond to the data performed by conventional micro-indentation (Eqs. (12)-(13)). 


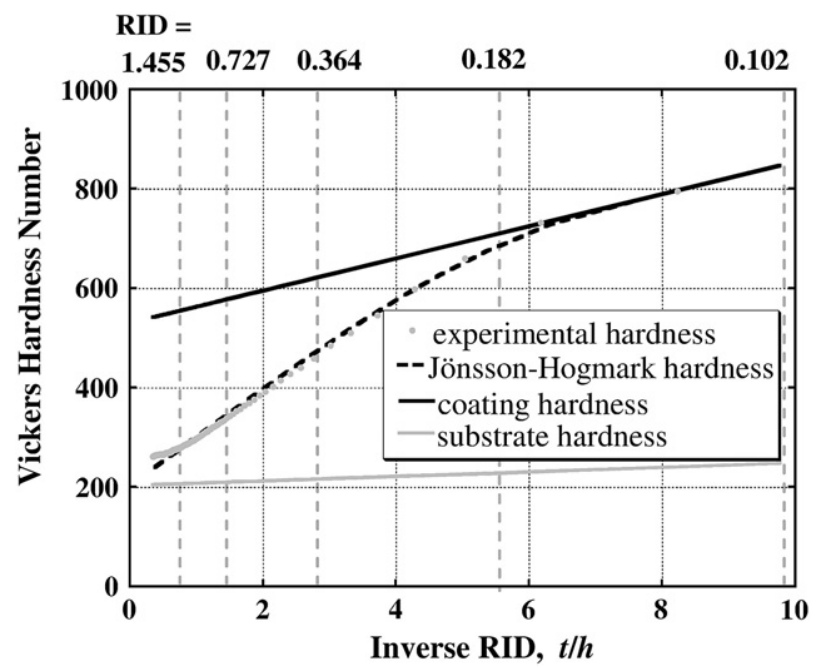

Fig. 5. Interpretation of the recorded data in Fig. 1 by plotting the Vickers hardness number versus the inverse RID $(t / h)$ and the indication of the range of data used for testing the robustness of the models ( $R I D \geq 0.102$ to $R I D \geq 1.455$ ). The coating and substrate hardness plots correspond to the data performed by conventional micro-indentation (Eqs. (12)-(13)).

In the same way, the substrate hardness, measured independently after removing of the coating, varied with the applied load such that:

$H_{s}=203+\frac{250}{h}=203\left(1+0.02239 \frac{t}{h}\right)$.

Based on these experimental data, we assumed first that both the coating and the substrate hardnesses were perfectly known. Then, we searched the parameters to fit the model curve with experimental data by least squares minimization for the three models under study so that the difference between the models and the experimental data was minimized. Table 1 reports the value of all constants involved in the models. We then considered the three "theoretical model curves" to compare the robustness of the models. These theoretical plots (corresponding perfectly to the model selected) were then perturbed to represent experimental uncertainties. Moreover, the data that corresponded to the smallest indentation depths were deleted to reflect the real case where the film is so thin that it is impossible to create indents that satisfy the requirement to obtain the hardness of the coating alone. All of the details in each step of this methodology are presented in the following section with the value of the proposed threshold and random noise.

\section{Results and discussion}

First, the data in Fig. 1 are considered. The true film and substrate hardnesses are, respectively stated as quoted in Eqs. (12)-(13). The

Table 1

Influence factors, $a$, film and coating hardnesses and fitting parameters used in the three models to obtain the 'theoretical model curves'; $0 \leq a \leq 1$.

\begin{tabular}{|c|c|c|c|}
\hline Model & $a$ & Hardness & Parameters \\
\hline $\mathrm{JH}$ & $a=\left\{\begin{array}{l}1, h \leq C t \\
\frac{2 C t}{h}-\frac{C^{2} t^{2}}{h^{2}}, h>C t\end{array}\right.$ & $\begin{array}{l}\text { Film: } \\
H_{0 f}=530 \mathrm{VHN} \\
\alpha_{f}=0.06112\end{array}$ & $C=0.140$ \\
\hline K & $\frac{1}{1+k_{k}\left(\frac{h}{t}\right)^{2}}$ & $\begin{array}{l}B_{f}=1781 \mathrm{VHN} \mu \mathrm{m} \\
\text { Coating: } \\
H_{0 f}=203 \mathrm{VHN}\end{array}$ & $\begin{array}{l}k_{k}=3.171 \\
k_{p}=1.122\end{array}$ \\
\hline PC & $\exp \left[-k_{p}\left(\frac{h}{t}\right)^{n_{p}}\right]$ & $\begin{array}{l}\alpha_{f}=0.02239 \\
B_{f}=250 \mathrm{VHN} \mu \mathrm{m}\end{array}$ & $n_{p}=0.836$ \\
\hline
\end{tabular}

composite hardness is thus represented as a function of the indentation depth. However, the indentation depth sampling does not have a linear evolution versus time. This sampling effect can affect the statistical estimation of the model parameters. This artifact can then lead to the introduction of a bias in the model coefficients. To avoid this bias, the sampling rate must be iid, i.e., independent and identically distributed random variables. In order not to be influenced by the indentation depth time distribution during the experiment, a linearization process was performed. A new indentation depth distribution is proposed with one hundred points. Depths are regularly distributed from the minimum $(5.6 \mu \mathrm{m})$ to the maximum $(158.7 \mu \mathrm{m})$ depth values and the corresponding hardnesses are then estimated using local smoothing tools. This new data set represents the hardness evolution and was used to test the robustness of models.

Second, for each model, the fitting parameters in the a-coefficients were calculated to best match the experimental results. This procedure led to "theoretical model curves" whose values are given in brackets in Table 1 . These parameters then remained unchanged during stages 3 and 4. It should be noted that the Jönsson and Hogmark model does not require any parameter estimation. Indeed, we assumed that the coating was plastically deformed $(C=0.140)$ because no cracks were observed near the print.

Third, the three previous curves were truncated by deleting the data corresponding to an indentation depth smaller than 10, 20, 40, or $80 \mu \mathrm{m}$, which correspond, respectively, to a relative experimental indentation depth $(h / t)_{\text {exp }}$ larger than $0.182,0.364,0.727$ or 1.455 . In doing so, we placed ourselves under the experimental conditions that correspond to the determination of the hardness of thin films, where it is not possible to measure the properties of the film only. Therefore, four curves were proposed for each model.

Fourth, random Gaussian noise centered at 0 with a standard deviation of $0.1 \mu \mathrm{m}$ was added to every indentation depth value. This stage was performed 5000 times by Monte Carlo simulations to give 5000 "experimental noise curves" for a given model. The hypothesis assumed that the experimental points were obtained independently from each other, as in the case of classic Vickers hardness tests (not instrumented). The problem of the instrumented test uncertainty is more complex and will be the subject of a further publication.

Fifth, for all of the 5000 previous curves and for every truncated set of data and every model, the film hardness ( $H_{0 f}$ and $\alpha_{f}$ in Eq. (3)) and the fitting parameters were computed with nonlinear regression in such a way that the quadratic difference between the "experimental noise curve" for a given model and the "theoretical model curve" was minimized. The downhill simplex method was developed for this aim, and the Nelder and Mead algorithm was used [27,28]. Fig. 6 (a1, b1, c1) represents the 5000 coating hardness evolutions corresponding to the experimental curves for the three models and a cut off of $40 \mu \mathrm{m}$ (i.e., the experimental values corresponding to a RID, $h / t$, smaller than 0.727 were ignored). The hardness evolution for the "experimental noise curve" and for the "theoretical model curve" is represented for the worst case (i.e., largest negative value of $\alpha_{f}$ ) in Fig. 6 (a2, b2, c2). For the Korsunsky (b) and Puchi-Cabrera (c) models, this value corresponds to an incorrect estimation of both $H_{0 f}$ and $\alpha_{f}$ compared to the expected values. $H_{0 f}$ was estimated to be $3190 \mathrm{VHN}(31.28 \mathrm{GPa})$ and $1283 \mathrm{VHN}(12.58 \mathrm{GPa}$ ) compared to the true $530 \mathrm{VHN}$ (5.2 GPa), respectively, and $\alpha_{f}$ was estimated as -0.2083 and -0.1479 compared to the true value of 0.06112 , respectively. Nevertheless, for each model, Fig. 6 (a2, b2, c2) shows that the estimation of these parameters can correctly predict the data of the "experimental noise curve". The worst case for the Jönsson-Hogmark model leads to an estimate of $535 \mathrm{VHN}$ for $\mathrm{H}_{\mathrm{Of}}$ and 0.04741 for $\alpha_{f}$. Thus, the film hardness is correctly estimated, and the error in its estimation is lower than the one observed in the Korsunsky and Puchi-Cabrera models.

Fig. 7 shows the coating hardness estimation corresponding to the same RID (40 $\mu \mathrm{m}$ cut-off) and shows that these values are centered on the theoretical ones. The JH model, with only two unknown quantities, $H_{0 f}$ and $\alpha_{f}$, is more robust than those with one or two additional fitting 

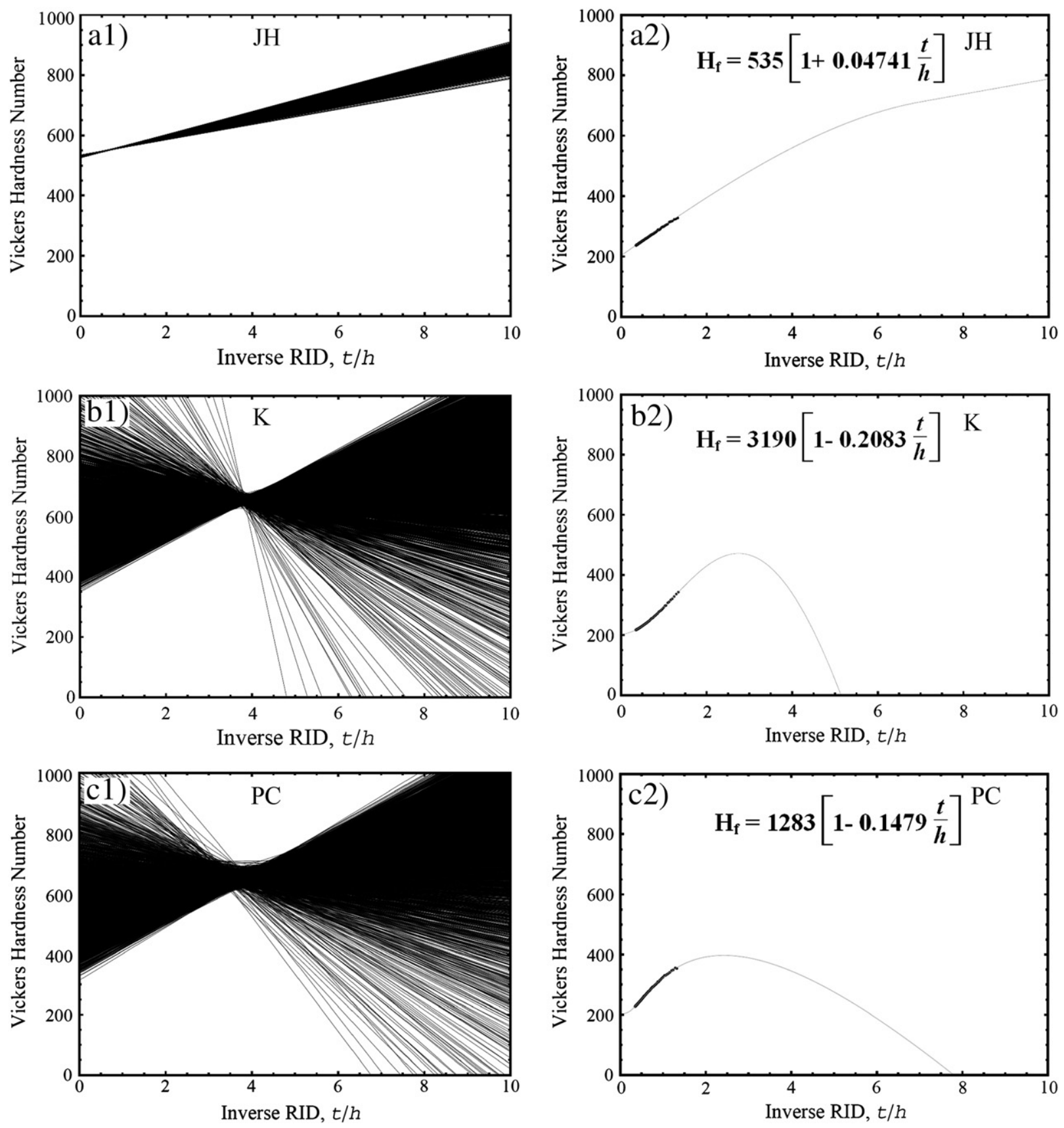

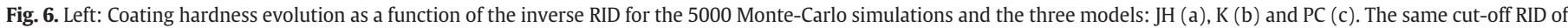

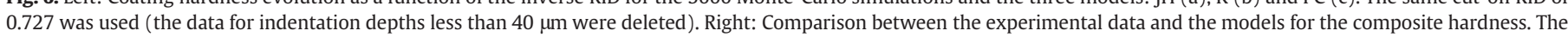

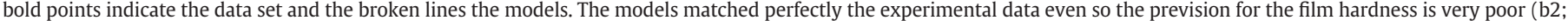
c2)

parameters and seems to be the best model to predict the coating hardness. Fig. 8 shows $H_{0 f}$ and $B_{f}$ estimations for the three models in the same diagram. Five thousand couples were estimated for each of the three models. The evolution of the three sets shows that these parameters are linearly correlated for each model. The linear evolution shown in Fig. 8 of $B_{f}$ versus $H_{0 f}$ demonstrates that all of the curves cut the same point in the hardness evolution diagram as a function of the inverse RID. This correlation was previously shown in each model in Fig. 6, where all of the curves intersect at the same pivot point. As observed earlier $[29,30]$, this pivot point is an indication of a strong relation between the parameter estimation used to describe the behavior. Similar correlations observed for all parameters of the $\mathrm{K}$ and PC models are not presented in this manuscript. Fig. 9 summarizes the results obtained for each cut-off in the estimations of the hardness parameters of the coating. Fig. 9 allows the user to determine the range of experimental data to be considered so as to allow for efficient determination of the coating mechanical properties. If the range of data is low enough, a strong deviation from the real values is observed, especially for the $\mathrm{K}$ and the PC models.

According to the results above, the following observations can be formulated for the different models under study:

1) The Jönsson Hogmark model (JH) is the most robust. According to the noise and/or the number of points considered, the coating hardness computed $\left(H_{0 f}\right.$ and $\left.\alpha_{f}\right)$ varies in a weak interval around the theoretical value of 530 VHN (Fig. 9) (Table 2), for example, the standard deviation, $\sigma$, is 2.41 for $H_{0 f}$ and $(h / t)_{\exp } \geq 0.182$. 

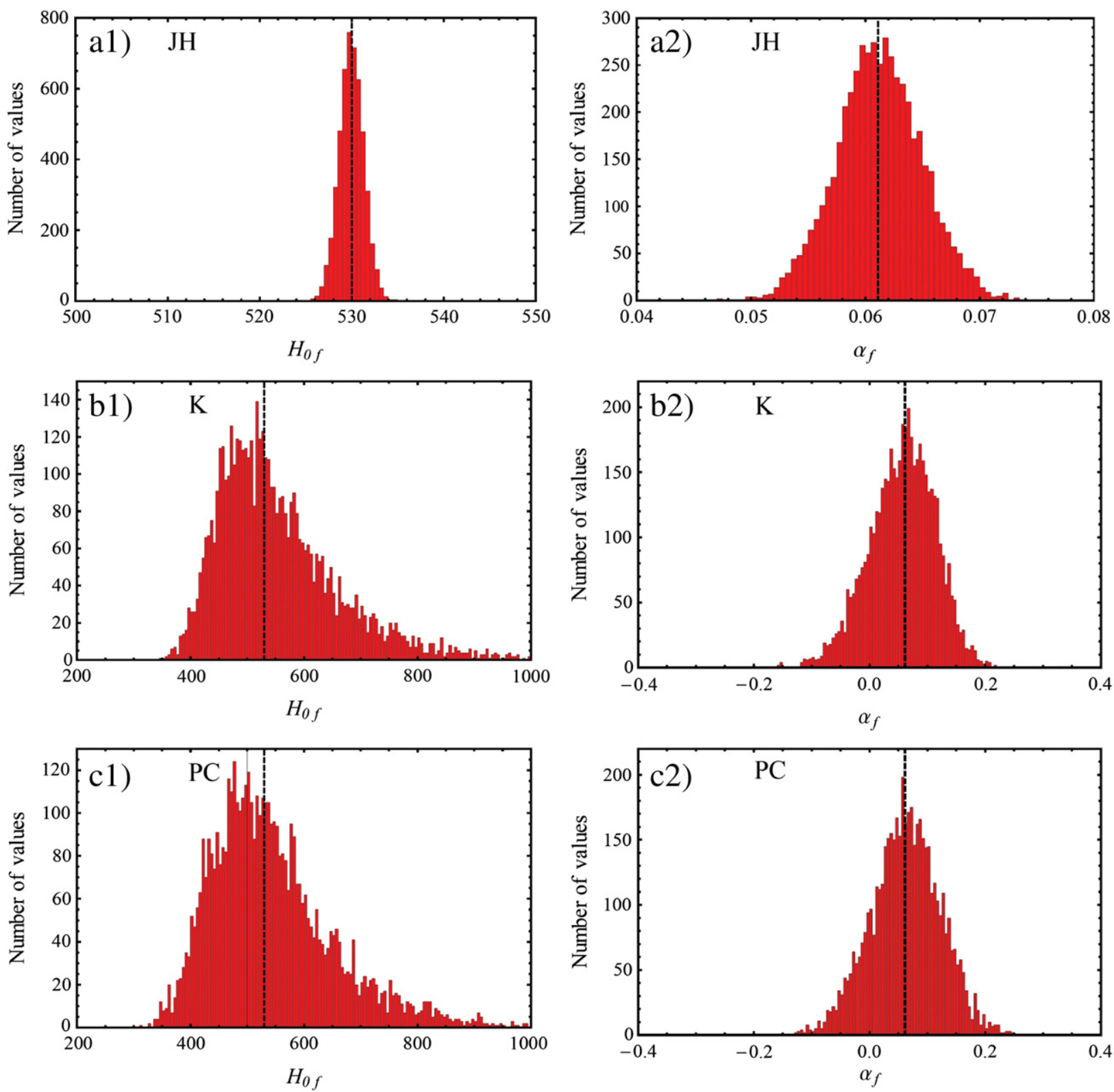

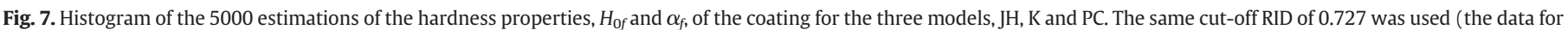
indentation depths less than $40 \mu \mathrm{m}$ were deleted).

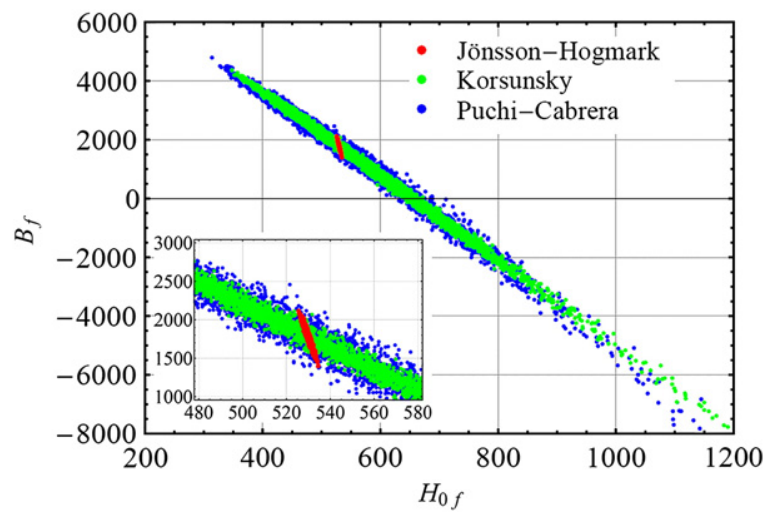

Fig. 8. Representation of the $5000\left(H_{0 f}, B_{f}\right)$ parameter estimations for the three models. The same cut-off RID of 0.727 was used (the data for indentation depths less than $40 \mu \mathrm{m}$ were deleted).
The evaluation of the coating hardness using noisy experimental results remains acceptable whether the diamond penetration depth is weak or strong. This result is contrary to the assertions generally found in the bibliography, which state that the $\mathrm{JH}$ model gives a poor fit when the indentation depth is shallower than the coating thickness or at the substrate-dominated end [14,15,17-19,31-33]. This contradiction is due to an incorrect use of the model by these authors. As underlined in the model presentation, it is necessary to take into account the hardness variation of the load without any simplifying hypotheses. Korsunsky et al. $[17,18]$ and Beegan et al. [33] claim that this model is observed to break down when tested outside the range of experimental values. We show in a recent paper [34] that this affirmation is related to an erroneous application of this model, which is in contradiction to its physical meaning. In addition, the above authors ignored the physical meaning of the model and used only its mathematical equation. If the ratio of the indentation depth to the coating thickness is 0.2 , the computation of Eq. (5) gives $a=-2.24$ and therefore a negative coating hardness 

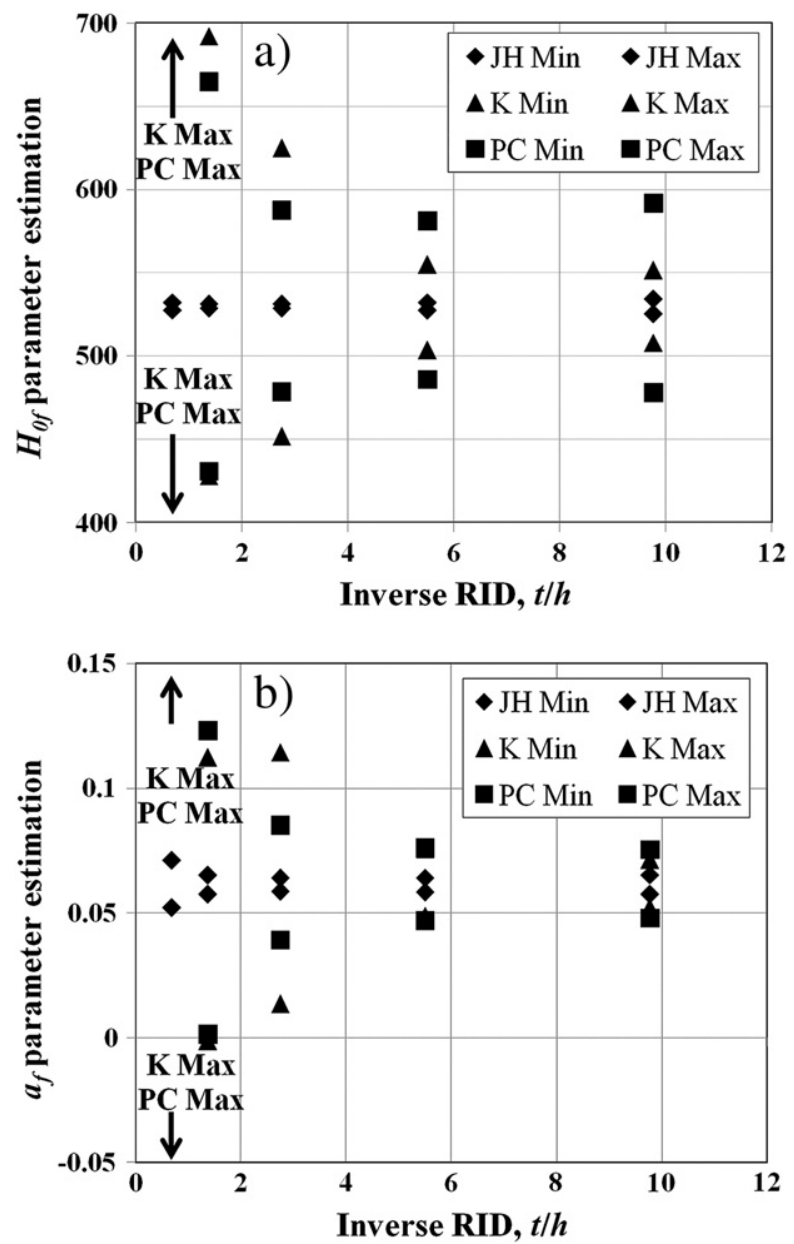

Fig. 9. Representation of the estimated parameter variation for the three models. For each parameter, $H_{0 f}$ (a) and $\alpha_{f}$ (b), the confidence interval $[\mu-\sigma, \mu+\sigma]$ is shown, where $\mu$ is the mean of the parameter estimations and $\sigma$ is its standard deviation. [JH Min, JH Max], [K Min, K Max] and [PC Min, PC Max] correspond to the confidence intervals of the JH, K and PC models, respectively. The right hand side points show the hardness parameters estimation without any cut-off ( $R I D \geq 0.102$ ).

in Eq. (4), which also corresponds to a negative indented area. Physically speaking, the $a$-coefficient varies between 0 and 1 . Moreover, only the case where $h>C t$ must be considered in Eq. (5). When the indentation depth is lower than the critical value $C t$, the measured hardness is the coating hardness.

2) The Korsunsky et al. model $(K)$ has a hardness variation range superior to that of the $\mathrm{JH}$ model for $H_{0 f}\left(\sigma=25.74\right.$ for $H_{0 f}$ and $\left.(h / t)_{\exp } \geq 0.182\right)$. The interrelationship between $H_{0 f}$ and $B_{f}$ is important (Fig. 8). If the RID is greater than $0.182, H_{0 f}$ may take values between 504 and 555, given the standard deviation. It was shown that some aberrant values are calculated when data corresponding to $h / t$ lower than 1.455 are deleted $\left(H_{0 f}>10^{15}\right.$ $H V)$.

3) The Puchi-Cabrera (PC) model presents a significant $H_{0 f}$ variation range (Table 2) $\left(\sigma=47.6\right.$ for $H_{0 f}$ and $\left.(h / t)_{\exp } \geq 0.182\right)$. If the critical RID increases and is greater than 1.455 , the standard deviation can be greater than the mean of the estimated values ( $\sigma=$ 651 for $H_{0 f}$ and $\left.(h / t)_{\exp } \geq 1.455\right)$. As with the Korsunsky model, there are negative slopes for the variation of the coating hardness for $(h / t)_{\exp } \geq 1.455$. In this model, all unknown quantities and fitting parameters are also correlated, which explains the lack of robustness: it is always possible to find a combination of $\left\{H_{0 f}, B_{f}\right.$, $k_{p}, n_{p}$ \} quadruplets to ensure that the $a$-coefficient verifies the experimental data in Eq. (2) regardless of the physical meaning of these coefficients. This explains why some authors consider that their model is valid when applied to coatings whose hardness is unknown and therefore cannot be verified.

By considering a fitting parameter $X$ as a variable in Eq. (9), the Korsunsky model may be improved to best match the experimental data if the data set is sufficiently large (one more degree of freedom), but the model is less robust because all coefficients are strongly correlated (results non-represented in this paper).

\section{Conclusion}

An electroless Ni-P coating deposited on a steel substrate, which was sufficiently thick to measure its hardness experimentally, was indented to test the robustness of three composite hardness models. The hardness variation versus the indentation depth or the diagonal print was recorded. These models were then used to describe the composite behavior of the "coating-substrate", and the parameters of every model were estimated to fit the experimental data using an inverse method approach. The three plots were considered the "experimental models curves" for testing the robustness of the models. For all models, excellent fits were obtained, provided that sufficient data were available. We progressively deleted experimental data corresponding to the lower indentation depths and applied Gaussian

Table 2

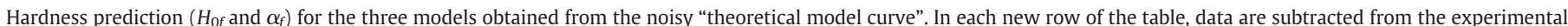

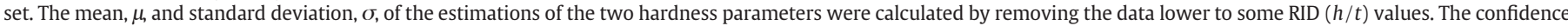

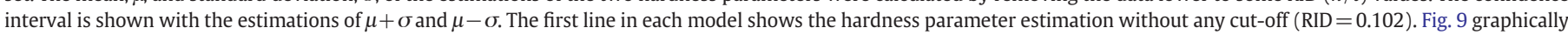
shows the corresponding confidence band evolution.

\begin{tabular}{|c|c|c|c|c|c|c|c|c|c|}
\hline & \multirow[t]{2}{*}{ RID } & \multicolumn{4}{|l|}{$H_{0 f}$} & \multicolumn{4}{|l|}{$\alpha_{f}$} \\
\hline & & $\begin{array}{l}\text { Mean } \\
\mu\end{array}$ & $\begin{array}{l}\text { Standard deviation } \\
\sigma\end{array}$ & $\mu-\sigma$ & $\mu+\sigma$ & $\begin{array}{l}\text { Mean } \\
\mu\end{array}$ & $\begin{array}{l}\text { Standard deviation } \\
\sigma\end{array}$ & $\mu-\sigma$ & $\mu+\sigma$ \\
\hline \multirow[t]{5}{*}{$\mathrm{JH}$} & 0.102 & 530 & 4.56 & 525 & 534 & 0.0614 & 0.00386 & 0.0575 & 0.0652 \\
\hline & 0.182 & 530 & 2.41 & 528 & 532 & 0.0612 & 0.00285 & 0.0584 & 0.0641 \\
\hline & 0.364 & 530 & 1.41 & 529 & 531 & 0.0612 & 0.00268 & 0.0586 & 0.0639 \\
\hline & 0.727 & 530 & 1.33 & 529 & 531 & 0.0613 & 0.00376 & 0.0575 & 0.0651 \\
\hline & 1.455 & 530 & 2.35 & 528 & 532 & 0.0616 & 0.00946 & 0.0521 & 0.0710 \\
\hline \multirow[t]{5}{*}{ K } & 0.102 & 530 & 21.73 & 508 & 552 & 0.0617 & 0.00963 & 0.0520 & 0.0713 \\
\hline & 0.182 & 529 & 25.74 & 504 & 555 & 0.0622 & 0.01348 & 0.0487 & 0.0757 \\
\hline & 0.364 & 538 & 86.69 & 452 & 625 & 0.0640 & 0.05047 & 0.0135 & 0.1145 \\
\hline & 0.727 & 560 & 132 & 428 & 692 & 0.0555 & 0.05676 & -0.0012 & 0.1123 \\
\hline & 1.455 & $8.10^{15}$ & $3.10^{17}$ & $-3.10^{17}$ & $3.10^{17}$ & 0.0353 & 0.16680 & -0.1315 & 0.2021 \\
\hline \multirow[t]{5}{*}{ PC } & 0.102 & 535 & 56.87 & 478 & 591 & 0.0617 & 0.01375 & 0.0479 & 0.0754 \\
\hline & 0.182 & 534 & 47.59 & 486 & 581 & 0.0615 & 0.01452 & 0.0470 & 0.0761 \\
\hline & 0.364 & 533 & 54.48 & 479 & 588 & 0.0622 & 0.02300 & 0.0392 & 0.0852 \\
\hline & 0.727 & 548 & 116.98 & 431 & 665 & 0.0623 & 0.06087 & 0.0014 & 0.1232 \\
\hline & 1.455 & 648 & 651.04 & -3 & 1299 & 0.2403 & 0.39918 & -0.1589 & 0.6394 \\
\hline
\end{tabular}


noise to simulate experimental errors. The Jönsson and Hogmark model was the most robust and the most effective because the fitting process returned reasonable values for the coating hardness. This efficiency was shown whether the indentation depth was high or low. This model was the most robust because it uses only two variables: the coating hardness and the hardness variation with the applied load. Some authors increase the number of fitting parameters to better fit the composite hardness curve with the experimental data. They find, as expected, that the quality of the fit increases as the number of parameters involved increases. They do not always reach the expected result and also decrease the robustness of their model while introducing some interrelationships between the coefficients. The results may be very different from the true hardness of the coating, as shown in Table 2. This behavior was shown with the Korsunsky model with three fitting parameters $\left(H_{0 f}, \alpha_{f}, k_{k}\right)$ and the Puchi-Cabrera model with four fitting parameters $\left(H_{0 f}, \alpha_{f}, k_{p}, n_{p}\right)$.

The reverse analysis to determine the film hardness from the composite hardness is not unique in the case of limited data and experimental errors. Moreover, adding fitting parameters to the composite model enhances the nonuniqueness. The Jönsson Hogmark model, with only two fitting parameters (the film hardness and the hardness variation with the applied load), is more robust than models with one or two additional parameters in predicting a realistic value of the film hardness.

\section{Acknowledgments}

We acknowledge Mr. Jean-Louis Verbrugge from the company "Verbrugge" for providing the experimental specimen and for financial support and Véronique Hague for her assistance in English.

\section{References}

[1] P.C. Yashar, W.D. Sproul, Vacuum 55 (1999) 179.

[2] H. Bückle, La Machine-Outil Française 206 (1965) 125.

[3] B. Jönsson, S. Hogmark, Thin Solid Films 114 (1984) 257.
[4] L.S. Palatnik, A.I. Il'inskii, G.V. Fedorov, V.S. D'Yachenko, Izv. Vyssh. Uchebn. Zaved. Fiz. 1 (1966) 122.

[5] J.K. Tuck, A.M. Korsunsky, D.G. Bhat, S.J. Bull, Surf. Coat. Technol. 139 (2001) 63.

[6] C. Gamonpilas, E.P. Busso, Mater. Sci. Eng. A380 (2004) 52.

[7] H. Bückle, L'essai de micro dureté et ses applications, Pub. Scientifiques et Techniques du Ministère de l'Air, NT90 Paris, 1960.

[8] G. Farges, D. Degout, Thin Solid Films 181 (1989) 365.

[9] M.M. Chaudhri, M. Winter, J. Phys. D Appl. Phys. 21 (1988) 370.

[10] A. Iost, R. Bigot, J. Mater. Sci. 31 (1996) 3573.

[11] O. Vingsbo, S. Hogmark, B. Jönsson, A. Ingermarsson, in: P.J. Blau, B.R. Lawn (Eds.), ASTM STP, 889, American Society for Testing and Materials, 1986, p. 257.

[12] A. Iost, R. Bigot, Surf. Coat. Technol. 80 (1996) 117.

[13] A. Thomas, Surf. Eng. 3 (1987) 117.

[14] E.S. Puchi-Cabrera, J.A. Berrios, D.G. Teer, Surf. Coat. Technol. 157 (2002) 185.

[15] M.H. Staia, E.S. Puchi, G. Castro, F.O. Ramirez, D.B. Lewis, Thin Solid Films 355 (356) (1999) 472.

[16] D. Chicot, J. Lesage, Thin Solid Films 254 (1995) 123.

[17] A.M. Korsunsky, M.R. McGurk, S.J. Bull, T.F. Page, Surf. Coat. Technol. 99 (1998) 171.

[18] J.R. Tuck, A.M. Korsunsky, R.I. Davidson, S.J. Bull, D.M. Elliot, Surf. Coat. Technol. 127 (2000) 1.

[19] E.S. Puchi-Cabrera, Surf. Coat. Technol. 160 (2002) 177.

[20] A.K. Bhattacharya, W.D. Nix, Int. J. Solids Struct. 24 (1988) 1287.

[21] L. Wang, S.I. Rokhin, Int. J. Solids Struct. 42 (2005) 3807.

[22] J. Malzbender, J.M.J. den Toonder, A.R. Balkenede, G. de With, Mater. Sci. Eng. R 36 (2002) 47.

[23] E. Reimann, in: Joint International Conference IMEKO TC3/TC5/TC20, VDI Berichte Book Series, volume 1685, 2002, p. 385.

[24] M. Griepentrog, C. Ullner, A. Dück, in: Joint International Conference IMEKO TC3/TC5/TC20, VDI Berichte Book Series, volume 1685, 2002, p. 105.

[25] ISO, Metallic Materials - Instrumented Indentation Test for Hardness and Materials Parameters ISO/FDSI 14577-1, -2, -3: 2002, , 2002. (Geneva, Switzerland).

[26] A. Martens, Handbuch der Materialienkunde für den Maschinenbau, Springer, Berlin, 1898.

[27] J.A. Nelder, R. Mead, Comput. J. 7 (1965) 308.

[28] W.H. Press, B.P. Flannery, S.A. Teukolsky, W.T. Vetterling, Numerical Recipes in C ++ , Cambridge University Press, Cambridge, 2002.

[29] A. Iost, J. Mater. Sci. 33 (1998) 3201.

[30] A. Iost, J. Lesage, Eng. Fract. Mech. 36 (1990) 585

[31] P.J. Burnett, D.S. Rickerby, Thin Solid Films 148 (1987) 41.

[32] D. Beagan, M.T. Laugier, Surf. Coat. Technol. 199 (2005) 32.

[33] D. Beegan, S. Chowdhury, M.T. Laugier, Thin Solid Films 516 (2008) 3813

[34] G. Guillemot, A. Iost, D. Chicot, Thin Solid Films 518 (2010) 2097. 